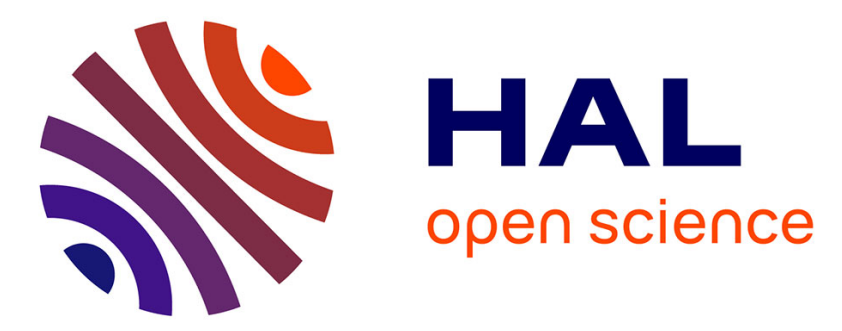

\title{
Decentralised Replenishment-Production Planning Optimisation Using Negotiation Rules in a Collaborative Network
}

Beatriz Andrés, Raul Poler, Josefa Mula, Manuel Díaz-Madroñero, Raquel Sanchis

\section{To cite this version:}

Beatriz Andrés, Raul Poler, Josefa Mula, Manuel Díaz-Madroñero, Raquel Sanchis. Decentralised Replenishment-Production Planning Optimisation Using Negotiation Rules in a Collaborative Network. 17th Working Conference on Virtual Enterprises (PRO-VE), Oct 2016, Porto, Portugal. pp.228240, 10.1007/978-3-319-45390-3_20. hal-01614615

\author{
HAL Id: hal-01614615 \\ https://hal.inria.fr/hal-01614615
}

Submitted on 11 Oct 2017

HAL is a multi-disciplinary open access archive for the deposit and dissemination of scientific research documents, whether they are published or not. The documents may come from teaching and research institutions in France or abroad, or from public or private research centers.
L'archive ouverte pluridisciplinaire HAL, est destinée au dépôt et à la diffusion de documents scientifiques de niveau recherche, publiés ou non, émanant des établissements d'enseignement et de recherche français ou étrangers, des laboratoires publics ou privés.

\section{(c)(1)}

Distributed under a Creative Commons Attribution| 4.0 International License 


\title{
Decentralised Replenishment-Production Planning Optimisation using Negotiation Rules in a Collaborative Network
}

\author{
Beatriz Andres ${ }^{1}$, Raul Poler ${ }^{1}$, Josefa Mula ${ }^{1}$, Manuel Díaz-Madroñero ${ }^{1}$ and Raquel \\ Sanchis ${ }^{1}$ \\ ${ }^{1}$ Research Centre on Production Management and Engineering (CIGIP). Universitat \\ Politècnica de València (UPV). Calle Alarcón, 03801 Alcoy, Spain, \\ \{bandres, rpoler, fmula, fcodiama, rsanchis\}@cigip.upv.es
}

\begin{abstract}
This paper proposes a decentralised planning optimisation approach by using mathematical programming and negotiation mechanisms in a collaborative network. Two partners addressing the replenishment and production stages are considered. Concretely, production scheduling plans and material requirement plans, modelled by two mixed-integer programming models, are modified according to the established negotiation rules between the two collaborative partners. The main contribution of this paper is the improvement of the replenishment and production plans upstream of the network; proposing a decentralised collaborative planning process. The validation of the proposal is done using data based on an automotive industry
\end{abstract}

Keywords: Decentralised Planning Optimisation, Mathematical Programming, Negotiation Mechanisms, Collaborative Networks, Automotive Industry

\section{Introduction}

Increasing competitive changes in the global market, combined with rapid advances in information technology have made that collaborative network planning is at the edge of the business practices of most of collaborative partners. Given the complexity of operations and the often-conflicting objectives [1] of the enterprises belonging to a collaborative network $(\mathrm{CN})$, such as, purchasing, , manufacturing, distribution and sales, it is essential to develop a unified and rigorous approaches to increase commitments and reduce discrepancies among the network partners. The effective integration of these different features is the main objective of the collaborative network planning [2]. Planning refers to the coordination and integration of key business activities undertaken by the network partners, from procurement of raw materials to distribution of finished products to the customer [3]. Nowadays, globalised markets are constantly changing, thus maintaining flexible, efficient and sustainable $\mathrm{CN}$ is essential to deal with the volatility prevailing in the business environment, which is constantly transforming, and with the variability of customer expectations.

In response to the challenge outlined, this paper proposes a decentralised collaborative planning approach that focuses on the negotiation of replenishmentproduction plans. The proposed approach centres its attention on two levels of the 
$\mathrm{CN}$ : a manufacturer and its supplier supporting the decentralised collaborative planning between (i) the integrated scheduling and replenishment plan computed by the manufacturer, identifying the quantities of finished products to produce, the sequence of production, the quantity of components required to produce the finished products and the period in which the components are demanded; and (ii) the scheduling plan computed by the supplier, identifying the quantity of components to produce with the main aim of supplying them to the manufacturer, minimising the products shortages. In order to support such collaboration in the planning process, negotiation mechanisms are proposed, in which each collaborative partner defines decision-making rules that will allow exchanging results on plans until an agreement between the scheduling plans of both, the manufacturer and the supplier, converge; obtaining a beneficial solution for both.

In this regard, the paper is organised as follows. Section 1 introduces the problem to be solved, raises the research question, and describes the research approach carried out. Section 2 presents the literature review. Section 3 proposes a decentralised collaborative approach that consists of two mixed-integer programming models, for both the manufacturer and the supplier. Moreover, collaborative negotiation mechanisms are presented. A use case is proposed in Section 4. Concluding remarks and future research lines are drawn in Section 5.

\subsection{Problem Description and Research Question}

The operational planning process, such as replenishment, production, inventory management and distribution processes, is relevant for the establishment of collaborative processes among networked partners [4]. Collaboration can be seen as the mutual participants' commitment to jointly solve problems. The collaborative network management has associated a higher degree of complexity; due to heterogeneous and autonomous partners take part in [5]. This involves that each collaborative partner defines different goal-based objectives [1], making attractive the proposal of approaches devoted to integrate all the nodes through the network planning. Considering the importance of collaboratively perform the planning process, among the enterprises of the same network, in terms of improving the CN relationships, this paper proposes a decentralised approach to support enterprises on the operational planning, from a collaborative perspective. The collaborative planning is focused on the replenishment and production planning process upstream of the $\mathrm{CN}$.

The following research question is raised to support the decentralised collaborative planning process, as the objective of this research: What would be a decentralised and collaborative approach to adequately support enterprises on the modelling, assessment and resolution of the replenishment-production planning from $a$ collaborative perspective?

The constructive research approach (CRA) [6] is used to answer the research question defined. Five are the phases determined in CRA: (i) identify a relevant problem subject to study, the problem in this research is defined by the discrepancies among the network partners, given the complexity of operations and the conflicting objectives of the $\mathrm{CN}$ enterprises; (ii) consider the background to solve the problem, this research is based on the operations research, production planning and $\mathrm{CN}$ 
management fields; (iii) propose a solution to the problem in an innovative way. Accordingly, decentralised scheduling-replenishment plans, modelled by two mixedinteger programming formulations, are modified according to the established negotiation rules between the two collaborative partners; (iv) identify the theoretical relevance of the solution and the theoretical contribution, the proposed research focuses on improving the $\mathrm{CN}$ long term operation; and finally (v) validate the solution, in this research a use case is provided. In the current phase of this research, the main aim is to provide models and negotiation mechanisms to achieve coherence between the replenishment and production plans of the manufacturers and suppliers that take part in the $\mathrm{CN}$, in order to promote sustainable collaboration.

\section{State of the Art}

Collaborative Planning. Different solutions have been proposed to jointly manage production, inventory and distribution planning activities [2][7][8]. The collaborative planning process can be considered as centralised (CDM) or decentralized (DDM) [9] decision models. Models that address the planning process according to the type of decision-making can be centralised [10] partially centralised [11] or decentralised [8]. To deal with uncertainty (in demand, materials, etc.) fuzzy approaches are proposed [12]. DDM allow the decision-making process to be more flexible [9]. To address the collaborative and decentralised planning process, the literature proposes multiobjective planning models [2].

Most of the models proposed in the literature focus on the centralised deterministic perspective, when dealing with collaborative planning. While decentralised models are focused on the downstream stages of the network, related with productioninventory management-distribution (third party logistics) planning processes. The main aim of this paper is to fill the gaps encountered with regards the decentralised collaborative planning processes, by focusing on the replenishment-production stages (upstream) of the network. In this context, they are pioneers the works by [13], who demonstrate the benefits of collaborative planning for improving material requirement plans by proposing a reference architecture, negotiation mechanisms and a collaborative multi-agent system as modelling approach. Related to these works, the main novelty of our proposal is the collaborative consideration between scheduling and replenishment plans. Additionally, it is important to highlight the use of mathematical programming formulations, traditionally used for centralised planning, as a modelling approach for collaborative and decentralised planning.

Negotiation. The establishment of DDM has associated the need for establishing negotiation mechanisms, defining pre-agreed business rules, and assessing and comparing planning alternatives using performance measurement techniques [11]. The literature review has allowed identifying different approaches dealing with nonhierarchical negotiations based on compensation schemes [13]. In this regard, it is 
worth to mention the work proposed by [8], which applies a non-hierarchical negotiation "a decentralised supply chain planning methodology (ADSCP)", allowing partners to create network plans by the simple exchange of information on the supply quantities. Here, the ADSCP methodology is adopted as the basis for the development of negotiation mechanisms.

\section{Decentralised Planning in Collaborative Networks}

The approach proposed to deal with the collaborative decentralised planning consists of the negotiation of two plans, each one pertaining to a different $\mathrm{CN}$ decision-maker, (i) the manufacturer that computes its scheduling plan (SP_M) and the material requirement planning (MRP_M); and (ii) the supplier that calculates its master scheduling plan (SP_S). In order to support the negotiation process, a collaboration mechanism is developed to link the two models from a decentralised and collaborative perspective [8].

\subsection{Manufacturer Scheduling and Materials Requirement Planning Model}

In this section, a mixed integer programming formulation for replenishmentscheduling planning based on [15] is described (see Table 1 for nomenclature). The first decision maker, the manufacturer, assumes the optimum scheduling planning and according to the quantity of products to produce, the manufacturer compute the MRP. Scheduling and MRP are integrated in the same model.

Table 1. Nomenclature model manufacturer

\begin{tabular}{l|l}
\hline Index & Set of products (finished goods and raw materials) \\
\hline$I$ & Set of finished goods \\
$J$ & Set of periods \\
\hline Parameters & \\
\hline$d_{i t}$ & Demand of product $i$ during time period $t$ \\
$t s_{i j}$ & Setup time from product $i$ to product $j$ \\
$c_{t}$ & Production capacity during time period $t$ \\
$I N V M A X_{i}$ & Available inventory capacity for product $i$ \\
$c v_{i t}$ & Coverage inventory: Minimum inventory required for product i \\
$I N V_{i 0}$ & Initial inventory of product i \\
$S R_{i t}$ & Scheduled receptions of product $i$ during time period $t$ \\
$b_{j i}$ & Quantity of $i$ to produce a unit of finished good $j$ \\
$t p_{i}$ & Required time to produce a unit of product $i$ \\
$c s_{i j}$ & Setup cost from product $i$ to product $j$ \\
$c i_{i t}$ & Inventory cost of product $i$ during time period $t$ \\
$c o t$ & Overtime cost during time period $t$ \\
$p c v_{i}$ & Penalty for soft inventory constraint violation for product $i$ \\
$b_{i 0}$ & Backorders of product $i$ during time period $t=0$ (initial) \\
$c b_{i}$ & Backorders cost of product $i$ \\
$c s u p_{t}$ & Production capacity of the supplier during time period $t$ \\
$M$ & Big number \\
$N$ & Number of finished goods \\
\hline
\end{tabular}




\begin{tabular}{l|l}
\hline \multicolumn{2}{l}{ Decision variables } \\
\hline$X_{i t}$ & Amount of $i$ to produce during time period $t$ \\
$Y_{i t}$ & 1 if product $i$ is produced during time period $t, 0$ otherwise \\
$S_{i j t}$ & 1 if a setup occurs from product $i$ to product $j$ during time period $t, 0$ otherwise \\
$I N V_{i t}$ & Inventory level of product $i$ at the end of time period $t$ \\
$Q_{i t}$ & Amount of product $i$ to order to suppliers \\
$T O V_{t}$ & Overtime hours during time period $t$ \\
$\alpha_{i t}$ & 1 if product $i$ is produced first during time period $t, 0$ otherwise \\
$\beta_{i t}$ & 1 if product $i$ is produced last during time period $t$, 0 otherwise \\
$\gamma_{i t}$ & 1 if machine is setup for product $i$ at the end of time period $t, 0$ otherwise \\
$\omega_{t}$ & Strictly positive when at least one product is produced in time period $t, 0$ otherwise \\
$\delta_{t}$ & 0 if exactly one product is produced during time period $t$, an unrestricted non-negative \\
$V_{i t}$ & number otherwise \\
$H_{i t}$ & auxiliary continuous variable to eliminate disconnected subtours \\
$B_{i t}$ & auxiliary variable to generate soft inventory constraint for product $i$ during time period $t$ \\
\hline
\end{tabular}

Objective function

Minz $=\sum_{i} \sum_{j} \sum_{t} c s_{i j} \cdot S_{i j t}+\sum_{i} \sum_{t} c i_{i t} \cdot I N V_{i t}+\sum_{t} c o_{t} \cdot T O V_{t}+\sum_{i} \sum_{t} p c v_{i} \cdot H_{i t}+\sum_{i} \sum_{t} c b_{i} \cdot B_{i t}$

Constraints

$\begin{array}{ll}I N V_{i 0}+X_{i t}-I N V_{i t}-b_{i 0}+B_{i t}=d_{i t} & \forall i \in J, t=1 \\ I N V_{i, t-1}+X_{i t}-I N V_{i t}-B_{i, t-1}+B_{i t}=d_{i t} & \forall i \in J, t>1 \\ I N V_{i, t-1}+S R_{i t}+Q_{i t}-I N V_{i t}=\sum_{j} b_{j i} \cdot X_{i t} & \forall i \in\{I\} \backslash\{J\}, t \\ I N V_{i, t} \leq I N V M A X_{i} & \forall i, t \\ I N V_{i t}+H H_{i t} \geq c v_{i, t} & \forall i \in J, t \\ X_{i t} \leq M \cdot Y_{i t} & \forall i \in J, t \\ \sum_{i \in J} t p_{i} \cdot X_{i t}+\sum_{i \in J} \sum_{j} t s_{i j} \cdot S_{i j t}-T O V_{t} \leq c_{t} & \forall t \\ \sum_{i \notin J} t p_{i} \cdot Q_{i t} \leq c \sup _{t} & \forall i \in J, t \\ Y_{i t} \leq \omega_{i t} & \forall i \in J, t \\ \sum_{i \in j} Y_{i t}-1 \leq(N-1) \delta_{t} & \forall t \\ \omega_{t} \leq \sum_{i \in j} \alpha_{i t} \leq 1 & \forall t \\ \omega_{t} \leq \sum_{i \in j} \beta_{i t} \leq 1 & \\ \alpha_{i t} \leq Y_{i t} & \forall t\end{array}$




$\begin{array}{ll}\beta_{i t} \leq Y_{i t} & \forall i \in J, t \\ \alpha_{i t}+\beta_{i t} \leq 2-\delta_{t} & \forall i \in J, t \\ \sum_{i \in j} \gamma_{i t}=1 & \forall t \\ \sum_{j} S_{j i t} \geq Y_{i t}-\alpha_{i t} & \forall i \in J, t \\ \sum_{j} S_{i j t} \geq Y_{i t}-\beta_{i t} & \forall i \in J, t \\ S_{i j t} \geq \gamma_{i, t-1}+\gamma_{j t}-\omega_{t}-1 & \\ S_{j i t} \geq \alpha_{i t}+\gamma_{j, t-1}-1 & \forall i \in J, i \neq j, t \\ S_{i j t} \geq \beta_{i t}+\gamma_{j t}-1 & \forall i \in J, i \neq j, t \\ V_{j t} \geq V_{i t}+N \cdot S_{i j t}-(N-1)-N \cdot \gamma_{i, t-1} & \forall i \in J, i \neq j, t \\ 0 \leq \omega_{t} \leq 1 & \forall i \in J, i \neq j, t \\ X_{i t}, I N V_{i t}, \delta_{t}, T O V_{t}, B_{i t}, H_{i t} \geq 0 & \forall t \\ S_{i j t}, Y_{i t}, \alpha_{i t}, \beta_{i t}, \gamma_{i t} \in\{0,1\} & \forall i, t\end{array}$

Objective function (1) minimizes all the performed setups, inventory holding, overtime costs, the penalty of finished goods inventory coverage violations, the backorders. Constraints (2) and (3) are typical inventory balance equations for finished goods allowing backorders and (4) for raw materials. Constraint (5) limits the inventory level for each product according to the available inventory capacity. Constraint (6) corresponds to inventory coverage extension for finished goods. In this case, and in order to avoid infeasibilities, it is set as a soft constraint with a penalty cost included in the objective function. Constraint (7) ensures that whenever $X_{i t} \geq 0$, decision variable $Y_{i t}$ is set at 1 . Constraint (8) establishes the production capacity limits by taking into account possible overtime decisions. Constraint (9) establishes the production capacity of the supplier. Constraints (10) to (17) determine which product is produced first and last during a given time period. They also find the product for which the machine is setup at the end of each time period. Constraints (18) and (19) apply whenever more than one product is produced during a single period. They force at least one $S_{i j t}$ 's to be 1 per product $i$, except when this product is either the first or the last product in the sequence. Constraint (20) forces a setup during production-free periods when the machine's setup state at the end of the period is not the same as the setup status at the end of the following period. Constraints (21) and (22) are needed to properly count the setups between the periods during which the machine is not idle, while Constraint (23) ensures the subtours elimination. Finally, Constraints (24) to (26) correspond to the binary and non-negativity properties of the decision variables.

\subsection{Supplier Master Production Scheduling Planning Model}

In this section, a mixed integer programming formulation for scheduling planning 
based on [15], is described for the supplier master production scheduling planning model (see Table 2 for nomenclature).

Table 2. Nomenclature model manufacturer

\begin{tabular}{|c|c|}
\hline \multicolumn{2}{|l|}{ Index } \\
\hline$I$ & Set of products (finished goods and raw materials) \\
\hline$T$ & Set of periods \\
\hline \multicolumn{2}{|c|}{ Parameters } \\
\hline$d_{i t}$ & Demand of product $i$ during time period $t$ \\
\hline INVMAX & Available inventory capacity for product $i$ \\
\hline$c v_{i t}$ & Coverage inventory: Minimum inventory required for product $\mathrm{i}$ \\
\hline$I N V_{i 0}$ & Initial inventory of product $\mathrm{i}$ \\
\hline$t p_{i}$ & Required time to produce a unit of product $i$ \\
\hline$c i_{i t}$ & Inventory cost of product $i$ during time period $t$ \\
\hline $\mathrm{cot}_{t}$ & Overtime cost during time period $t$ \\
\hline$p c v_{i}$ & Penalty for soft inventory constraint violation for product $i$ \\
\hline $\operatorname{csup}_{t}$ & Production capacity of the supplier during time period $t$ \\
\hline $\operatorname{csh}_{i}$ & Shortage cost per unit of product $i$ \\
\hline$M$ & Big number \\
\hline \multicolumn{2}{|c|}{ Decision variables } \\
\hline$X_{i t}$ & $\begin{array}{l}\text { Amount of } i \text { to produce during time period } t \\
\text { Inventory level of product } i \text { at the end of time period } t\end{array}$ \\
\hline$I N V_{i t}$ & Offered supply quantity of product $i$ during time period $t$ \\
\hline$Q_{i t}$ & Overtime hours during time period $t$ \\
\hline$T O V_{t}$ & Supply shortage of product $i$ during time period $t$ \\
\hline $\begin{array}{l}S H_{i t} \\
H_{i t}\end{array}$ & $\begin{array}{l}\text { Auxiliary variable to generate soft inventory constraint for product } i \text { during time } \\
\text { period } t\end{array}$ \\
\hline
\end{tabular}

Objective function

$$
\operatorname{Minz}=\sum_{i} \sum_{t} c i_{i t} \cdot I N V_{i t}+\sum_{t} c o_{t} \cdot T O V_{t}+\sum_{i} \sum_{t} p c v_{i} \cdot H_{i t}+\sum_{i} \sum_{t} c s h_{i} \cdot S H_{i t}
$$

Constraints

$$
\begin{array}{ll}
I N V_{i, t-1}+X_{i t}-I N V_{i t}=Q_{i t} & \forall i, t \\
I N V_{i, t} \leq I N V M A X_{i} & \forall i, t \\
I N V_{i t}+H_{i t} \geq c v_{i, t} & \forall i, t \\
\sum_{i} t p_{i} \cdot X_{i t}-T O V_{t} \leq c \sup _{t} & \forall t \\
X_{i t}+S H_{i t}=d_{i t} & \forall i, t \\
X_{i t}=Q_{i t} & \forall i, t \\
X_{i t} I N V_{i t} T O V_{t}, H_{i t} \geq 0 & \forall i, t
\end{array}
$$

Objective function (27) minimizes all the inventory holding, overtime costs, the penalty of finished goods inventory coverage violations and the supply shortage. Constraint (28) is typical inventory balance equation. Constraint (29) limits the 
inventory level for each product according to the available inventory capacity. Constraint (30) corresponds to inventory coverage extension for finished goods. In this case, and in order to avoid infeasibilities, it is set as a soft constraint with a penalty cost included in the objective function. Constraint (31) establishes the production capacity limits of the supplier by taking into account possible overtime decisions. Constraint (32) establishes that the quantities demanded by the manufacturer are the same as the products produced by the supplier plus the shortage quantity of products. Constraint (33) indicates what the suppliers produces is the same as what is supplied to the manufacturer. Finally, Constraints (34) correspond to the non-negativity properties of the decision variables.

\subsection{Negotiation Mechanism for the collaborative planning process}

In this section a negotiation mechanism is proposed to support the network partners in the collaborative planning process. The negotiation mechanism is characterised by the decision-making rules, defined by the different partners involved in the collaborative planning .These decision-making rules allow to: (i) support the decision-making process and (ii) characterise the collaborative planning process by solving the differences among the planning activities of the parties involved. The decisionmaking rules should aim for a Win-Win outcome in order to meet the interests of all the sides involved. An example of decision-making rules is provided next with the main aim of guiding the enterprises, involved in the decentralised replenishmentproduction planning, in the collaboration process:

- Stockout Rule: This rule guarantees that at the end of the planning horizon the actual stock is higher than the minimum stock defined.

- Backorders Rule: It ensures that no demand delays are allowed at each period.

- Supplied quantity Rule: The quantity of components to be supplied (by the $S$ ) should be within a target range defined by the $M$.

- Inventory/Overtime/Setup costs Rule: The inventory/overtime/setup costs are defined in a bounded range.

Having identified the decision-making rules, the enterprises involved in the collaborative planning process start with the negotiation mechanism. The proposed negotiation mechanism, based on [8], is described next (Fig.1):

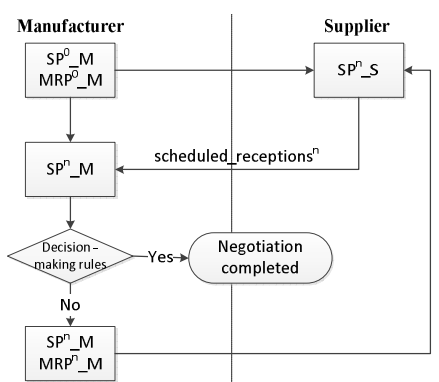

Figure 1. Overview of the negotiation steps 
Step 1. The manufacturer $(M)$ starts to compute the integrated replenishmentscheduling plan $\left(S P_{-}^{0} M, M R P \_M\right)$, given a planning horizon, depending on what to serve to the end customer (end-customer demand). According to the results obtained in the integrated replenishment-scheduling plan, $M$ obtains the replenishment needs of the raw material or semi-elaborated components $\left(M R P^{0}{ }_{-} M\right) . M$ releases the replenishment needs to the supplier $(S)$ (manufacturer demand).

Step 2. $S$ computes its scheduling plan $\left(S P^{n} \_S\right)$, according to demand given by $M$. In case the $S$ cannot satisfy the demand given by $\mathrm{M}, S$ communicates to $M$ the quantities that can serve $\left(Q_{i t}\right.$ : Offered supply quantity of product $i$ during period $\left.t\right)$

Step 3. $M$ generates a scheduling plan for the given offered supply quantity and considering the end-customer demand, so as to minimize $M$ total costs, and meet the demand; therefore no backorders are allowed. In this step, the obtained replenishment needs are limited by the amounts of components offered by supplier in the previous step.

Step 4.1. On the one hand, if the decision-making rules are achieved (end-customer demand reached, no backorders for the manufacturer, no shortages for the supplier, etc.) and the requested supply quantity of $M d_{i t}$ corresponds to the $Q_{i t}$ given by $S$, the negotiation procedure is completed.

Step 4.2. On the other hand, if the decision-making rules are not achieved, the negotiation process continues. Each iteration in the negotiation process is numbered as $n$. In this regard, $M$ generates a new replenishment-scheduling plan $\left(S P^{n}{ }_{-} M\right.$, $M R P^{n} \_M$ ) considering a new input data as regards the sequence and the quantity of products to produce in each period that allows accomplishing the decision makingrules and satisfying the demand with no backorders. $M$ reports to $\mathrm{S}$ the requested supply quantity in order to fulfil the given demand of end customer (manufacturer demand).

Step 5. $S$ generates a new scheduling plan $\left(S P^{n} \_S\right)$, considering its internal production capacity and the manufacturer demand. $S$ reports the new available supply quantity to $M$. Then the network nodes proceeds again with Step 3.

\section{Numerical Example}

This section presents the application of the proposed decentralized planning approach with a numerical example inspired in a real world automotive supply chain consisting of a supplier and a manufacturer. Both members by applying the proposed coordination mechanism achieve a compromise solution based on the coincidence of the amounts of components offered by supplier and the amounts of components requested by the manufacturer in order to meet the final customer demand following the stockout and backorders rules presented in the previous section, as well as a warehousing limitation rule for final products and components. Among them, the warehousing limitation and backorders rule in the last period are considered hard constraints while the stockout rule is considered as a soft constraint with a 
corresponding penalty. The mathematical programming models related to the supplier and manufacturer and the corresponding coordination mechanism have been in the MPL language V4.2. The resolution has been carried out with Gurobi 5.6.3 solver in a desktop computer with $4 \mathrm{~Gb}$ RAM. The input data and the model solution values were processed with the Microsoft Access database (2010) which was useful for the exchange of information between supplier and manufacturer models.

This study considers one finished good produced at manufacturer by processing one component obtained from the supplier in the same proportion over the four time periods considered. The demand levels at manufacturer are 3, 5, 11 and 0 , respectively. The rest of manufacturer parameters are presented in Table 3 . The initial backorders and scheduled receptions for each period are considered null and initial inventories are set according to stockout decision-making rule. The values for decision-making rules at manufacturer are presented in Table 4.

Table 3. Manufacturer parameters

\begin{tabular}{cc}
\hline Parameter & Value \\
\hline$c_{t}$ & $24 \mathrm{~h}$ \\
$t p_{i}$ & $1 \mathrm{~h} /$ unit \\
$c i_{(i=1) t}$ & $10 €$ \\
$c i_{(i=2) t}$ & $7 €$ \\
$c o_{t}$ & $100 €$ \\
$c b_{i}$ & $1000 €$ \\
\hline
\end{tabular}

Table 4. Values for decision making rules at manufacturer

\begin{tabular}{lll}
\hline Decision-making rule & Indexes & Values \\
\hline Stockout & $i=1, t$ & 3 units \\
Stockout & $i=2, t$ & 3 units \\
Backorders & $i=1, t=4$ & 0 units \\
Warehousing space & $i=1, t$ & 7 units \\
Warehousing space & $i=2, t$ & 7 units \\
\hline
\end{tabular}

The supplier parameters are presented in Table 5. The initial inventories are also set according to the stockout decision-making rule. The values for decision-making rules at supplier are presented in Table 6.

Using this data set a total of three iterations of the proposed coordination mechanism are needed to obtain a satisfactory replenishment-production planning according to the hard (backorders and warehousing limitations) and soft (stockout) decision rules defined for each member of the considered supply chain. The results obtained after the third iteration are presented in Table 7.

Table 5. Supplier parameters

\begin{tabular}{cc}
\hline Parameter & Value \\
\hline capsup $_{t}$ & $10 \mathrm{~h}$ \\
$t p_{i}$ & $1 \mathrm{~h} / \mathrm{unit}$ \\
$c i_{i t}$ & $7 €$ \\
$c o_{t}$ & $100 €$ \\
$c s h_{i}$ & $1000 €$ \\
\hline
\end{tabular}

Table 6. Values for decision making rules at supplier

\begin{tabular}{lll}
\hline Decision-making rule & Indexes & Values \\
\hline Stockout & $i=2, t$ & 3 units \\
Warehousing space & $i=2, t$ & 7 units
\end{tabular}


Table 7. Results obtained from the proposed coordination mechanism

\begin{tabular}{lccc}
\hline & Iteration 1 & Iteration 2 & Iteration 3 \\
\hline Supply chain member & Manufacturer & Supplier & Manufacturer \\
\hline $\begin{array}{l}\text { Decision-making rules } \\
\text { matched }\end{array}$ & $\begin{array}{c}\text { Stockout } \\
\text { Backorders } \\
\text { Warehousing space }\end{array}$ & $\begin{array}{c}\text { Stockout } \\
\text { Warehousing space }\end{array}$ & $\begin{array}{c}\text { Stockout } \\
\text { (with flexibility) } \\
\text { Backorders } \\
\text { Warehousing space }\end{array}$ \\
\hline Exceptions & & Inventory for product \\
& Infinite production & & $i=1$ in periods $t=3$ and \\
& capacity for supplier & & $t=4$ is equal to 2 units \\
\hline
\end{tabular}

As shown in Table 7, the coordination mechanism obtains a replenishment-production plan according to the established decision-making rules at each node of the considered supply chain with a minimum deviation. The possibility of introducing the stockout decision rule as a soft constraint allows to focus on strict decision areas in the automotive industry such as maximum warehousing levels and backorders although minimum desired inventory levels are not obtained for only two periods.

\section{Conclusions}

In this paper, two decentralised scheduling models dealing with the replenishment and production stages of a $\mathrm{CN}$ have been used through a mathematical programming approach. The decentralised collaborative planning approach has been supported by a negotiation mechanism that allows modifying the quantities of components requested by the manufacturer and the quantities of supply offered by the supplier, with the main aim of minimising the shortages in the supply and the backorders to the final customer. The proposed approach allows promoting collaboration between the replenishment and production stages of the $\mathrm{CN}$. In future research lines, negotiation could be performed using the multi-agents paradigm by programming them based on automatic decision-making rules agreed by both network nodes. Another future work could be led to apply the proposed approach in a real size $\mathrm{CN}$. 
Acknowledgments. "The research leading to these results is in the frame of the "Cloud Collaborative Manufacturing Networks" (C2NET) project which has received funding from the European Union's Horizon 2020 research and innovation programme under grant agreement No 636909"

\section{References}

1. Andres, B., and Poler R.: Dealing with the Alignment of Strategies within the Collaborative Networked Partners, IFIP Int. Fed. Inf. Process. 450, pp.13--21 (2015).

2. Gupta, A. and Maranas, C.D.: Managing demand uncertainty in supply chain planning, Comput. Chem. Eng. 27, pp. 1219--1227 (2003).

3. Gupta, A. and Maranas, C.D.: A hierarchical Lagrangean relaxation procedure for solving midterm planning problems, Ind. Eng. Chem. Res. 38, pp. 1937--1947 (1999).

4. Andres, B., Poler, R. and Hernández, J.E.: An Operational Planning Solution for SMEs in Collaborative and Non-Hierarchical Networks, Lect. Notes Bus. Inf. Process. 164, pp 46-56 (2013).

5. Camarinha-Matos, L.M. and Afsarmanesh, H.: Collaborative networks: a new scientific discipline, J. Intell. Manuf. 16, pp. 439--452 (2005).

6. Kasanen, E., Lukka, K. and Siitonen, A.: The constructive approach in management accounting research, J. Manag. Account. Res. 5, pp. 243--264 (1993).

7. Dudek, G. and Stadtler, H.: Negotiation-based collaborative planning between supply chains partners, Eur. J. Oper. Res. 163, pp. 668--687 (2005).

8. Jung, H., Chen, F. and Jeong, B.: Decentralized supply chain planning framework for third party logistics partnership, Comput. Ind. Eng. 55, pp. 348--364 (2008).

9. Schneeweiss, S.: Distributed decision making in supply chain management, Int. J. Prod. Econ. 84, pp. 71-83 (2003).

10. Alemany, M.M.E., Alarcón, F., Lario, F.C. and Boj, J.J.: An application to support the temporal and spatial distributed decision-making process in supply chain collaborative planning, Comput. Ind. 62, pp. 519--540 (2011).

11. Pibernik, R., and Sucky, E.: An approach to inter-domain master planning in supply chains, Int. J. Prod. Econ. 108, pp. 200--212 (2007).

12. J. Mula, J., Peidro, D. and Poler, R.: Optimization models for supply chain production planning under fuzziness, Stud. Fuzziness Soft Comput. 31, pp. $397--422$ (2014).

13. Hernández J.E., A.C. Lyons, J. Mula, R. Poler, J. Ismail. Supporting the collaborative decision-making process in an automotive supply chain with a multi-agent system, Prod. Plan. Control 25, 662-678 (2014).

14. Mula, J., Poler, R. and Garcia J.P.: MRP with flexible constraints: A fuzzy mathematical programming approach, Fuzzy Sets Syst. 157, pp.74--97 (2006).

15. Andres, B. Mula, J., Diaz Madroñero, F.M., Poler, R. Sanchis, R.: Capacitated lot-sizing and scheduling problem for second-tier suppliers in the automotive sector. CIO-ICIEOMIISE-AIM International Joint Conference (IJC2016), July 13th to 15th, 2016 - TECNUNSchool of Engineering - San Sebastian, Spain (2016) Forthcoming. 